\title{
Commentary: Seeing is believing: Quality assurance with endovascular scopes
}

\author{
Derrick Y. Tam, MD, and Stephen E. Fremes, MD, MSc
}

\author{
From the Division of Cardiac Surgery, Schulich Heart Centre, Department of Surgery, Sunnybrook Health Sci- \\ ences Centre, University of Toronto, Toronto, Ontario, Canada. \\ Disclosures: Authors have nothing to disclose with regard to commercial support. \\ Received for publication Aug 1, 2018; accepted for publication Aug 4, 2018. \\ Address for reprints: Stephen E. Fremes, MD, MSc, Division of Cardiac Surgery, Schulich Heart Centre, Depart- \\ ment of Surgery, Sunnybrook Health Sciences Centre, 2075 Bayview Ave, Room H4 05, Toronto, ON, M4N \\ 3M5 Canada (E-mail: Stephen.fremes@sunnybrook.ca). \\ J Thorac Cardiovasc Surg 2019;157:e187-8 \\ $0022-5223 / \$ 36.00$ \\ Copyright (c) 2018 by The American Association for Thoracic Surgery \\ https://doi.org/10.1016/j.jtcvs.2018.08.003
}

The long-term success of coronary artery bypass grafting $(\mathrm{CABG})$ is predicated on sustained graft patency. In a randomized clinical trial comparing aprotinin use with placebo, early angiography was performed at 11 days and found that more than $10 \%$ of saphenous vein grafts were occluded in 703 patients. ${ }^{1}$ In the PREVENT IV multicenter trial of 3014 patients undergoing CABG who underwent angiographic follow-up at 1 year, up to $45 \%$ of patients had at least 1 vein graft occluded. ${ }^{2}$ Graft occlusion has been shown to be associated with early perioperative myocardial infarction and late composite end point of death, myocardial infarction, or repeat revascularization. ${ }^{2}$ Graft failure is multifactorial; in the perioperative period, early failure is likely related to technical factors, including the quality of the anastomosis. Standard techniques to assess graft flow and anastomosis quality include probing of the anastomosis, palpation for graft pulsatility, and abnormal hemodynamics, electrocardiogram, and transesophageal echocardiography findings. Multiple technologies have been studied to allow surgeons to more reliably assess intraoperative graft patency. The goal is to identify intraoperative graft patency, which can be revised before the patient leaves the operating room. The most commonly used technique is transit time flow measurement (TTFM). The European Society of Cardiology recommends the routine use of intraoperative graft flow measurements (recommendation: IIa, level of evidence: C). ${ }^{3}$ TTFM has been studied in a subset of 1607 patients from the Randomized On/Off Bypass trial. Low TTFM was associated with worse 1-year angiographic patency compared with normal flow, and patients with low flow were more likely to undergo intraoperative graft revision. ${ }^{4}$ Nonetheless, despite excellent reproducibility and ease of use, TTFM has been criticized for its low sensitivity and specificity. ${ }^{5,6}$ Furthermore, TTFM does not provide anatomic imaging information. Epicardial ultrasound has been proposed as an important adjunct

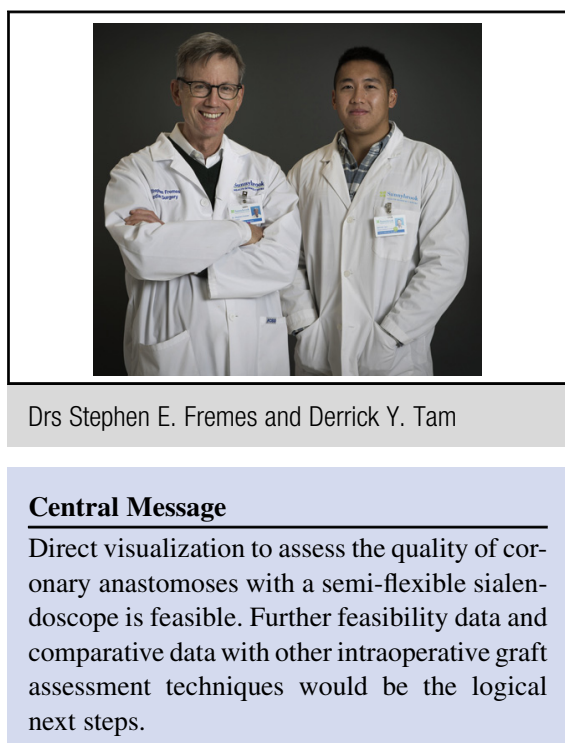

See Article page e183.

to TTFM. ${ }^{5}$ Epicardial ultrasound can be used to localize the optimal anastomosis site and assess the quality of the distal and proximal anastomosis. The addition of fluorescent indocyanine green angiography to TTFM at the time of CABG was studied in the randomized trial of 106 patients. The sensitivity and specificity of indocyanine green angiography were $83.6 \%$ and $100 \%$ compared with $25 \%$ and $98.4 \%$, respectively, with TTFM.

In this issue of the Journal, Hassanein and colleagues ${ }^{8}$ present the use of a video-assisted intraoperative direct visualization of anastomosis using a $1.3-\mathrm{mm}$ semiflexible sialendoscope introduced directly into the graft. They demonstrate that a sialendoscope can differentiate between a good-quality anastomosis and one that is compromised by comparing images of a distal anastomosis with those of an end-to-side anastomosis performed with a leftover vein with an intentional stitch placed into the backwall of the coronary artery (ie, a positive control). There were no intraoperative graft revisions or early morbidity or mortality in this small group of 17 patients. There are important limitations to this study: This was a single-arm study to examine feasibility with a small sample size that was not powered to detect early morbidity or mortality or postoperative patency. There may be feasibility issues that become apparent in larger patient samples, such as with smaller conduits, with grafts going to the back of the heart and in off-pump situations. There 
was no comparison with a reference standard in this assessment; thus, the sensitivity and specificity of this diagnostic test are not known. The time horizon was limited to the early postoperative period, and thus conclusions cannot be drawn regarding any potential benefit or harm of this technology beyond the perioperative period. In addition, although this technique allows for the assessment of the anastomosis site, there is no information regarding the flow through the graft. Flow may still be poor despite a perfectly anastomosed graft as a result of competitive flow, kinking, or placing the conduit on the wrong coronary artery. Thus, this technology may be an important adjunct to TTFM to differentiate between technical and nontechnical causes of poor flow. Finally, there is controversy surrounding the utility of intraoperative assessment of graft flow. Revision of a graft with marginal flow may not necessarily improve outcomes because the anastomosis in question may have been technically challenging from the start. Thus, graft revision may have the potential for harm and highlights the importance of integrating all available information coupled with strong clinical judgment and experience. Despite these limitations, this study provides the impetus to consider a pilot randomized clinical trial to compare the use of coronary endoscopy in addition to the standard of care in both early safety and efficacy in improving outcomes after CABG in a larger sample of patients. Seeing may be believing in coronary endoscopy.

\section{References}

1. Alderman EL, Levy JH, Rich JB, Nili M, Vidne B, Schaff H, et al. Analyses of coronary graft patency after aprotinin use: results from the international multicenter aprotinin graft patency experience (IMAGE) trial. J Thorac Cardiovasc Surg. 1998;116:716-30.

2. Alexander JH, Hafley G, Harrington RA, Peterson ED, Ferguson TB Jr, Lorenz TJ, et al. Efficacy and safety of edifoligide, an E2F transcription factor decoy, for prevention of vein graft failure following coronary artery bypass graft surgery: PREVENT IV: a randomized controlled trial. JAMA. 2005;294:2446-54.

3. Kolh P, Windecker S, Alfonso F, Collet JP, Cremer J, Falk V, et al. 2014 ESC/EACTS guidelines on myocardial revascularization: the task force on myocardial revascularization of the European Society of Cardiology (ESC) and the European Association for Cardio-Thoracic Surgery (EACTS). Developed with the special contribution of the European Association of Percutaneous Cardiovascular Interventions (EAPCI). Eur J Cardiothorac Surg. 2014;46:517-92.

4. Quin J, Lucke J, Hattler B, Gupta S, Baltz J, Bishawi M, et al. Surgeon judgment and utility of transit time flow probes in coronary artery bypass grafting surgery. JAMA Surg. 2014;149:1182-7.

5. Kieser TM, Taggart DP. Current status of intra-operative graft assessment: Should it be the standard of care for coronary artery bypass graft surgery? J Card Surg. 2018;33:219-28.

6. Takami Y, Takagi Y. Roles of transit-time flow measurement for coronary artery bypass surgery. J Thorac Cardiovasc Surg. 2018;66:426-33.

7. Desai ND, Miwa S, Kodama D, Koyama T, Cohen G, Pelletier MP, et al. A randomized comparison of intraoperative indocyanine green angiography and transit-time flow measurement to detect technical errors in coronary bypass grafts. J Thorac Cardiovasc Surg. 2006;13:585-94.

8. Hassanein W, Saleh A, Magdy EA, Abdelrahman M. Endovascular visual verification of anastomotic patency in coronary bypass. J Thorac Cardiovasc Surg. 2019;157:e183-5. 